\title{
Measuring nurses' productivity at Assiut University Hospital
}

\author{
Safaa Abd Elaziz Rashed, Mohamed Ali Mohamed Al Torky \& Sahar Mohamed Morsey \\ Assistant Lecturer of Nursing Administration, Faculty of Nursing, Sohag University, Egypt. \\ Professor of Community Health Faculty of Medicine, Sohag University, Egypt. \\ Assistant Professor of Nursing Administration, Faculty of Nursing - Assiut University, Egypt.
}

\begin{abstract}
Productivity is a critical determent of the health care system. This study aims at measuring nurses' productivity, Subjects and Methods: The sample consisted of nurses working at medical units, surgical units, casualty and post operative ICUs. Their total numbers are ninety five nurses. Data collected for the period of six months by observation of nurses and by interviewing nurses for personal data. Tools of data collection: The data collected by using socio-demographic questions, nurses activity analysis, productivity formula Results: Nursing productivity was forty percent at medical units, fifty two percent at surgical unit, one hundred five percent at casualty ICU, and one hundred fifty two percent at post operative ICU. Conclusions: Duration of activities observed among staff nurses (64380) minutes observed among staff nurses for giving care at patient centered activities, while for personnel centered activity level it was (60) minutes for clerical skill level. The lowest percent of productivity at medical unit, surgical unit, post operative intensive care unit, while the highest percent at casualty ICU. Recommendations: Providing training program for nurses to improve performance, decrease wasted time, and increase patient care time. Productivity should be periodically measured to monitor the performance of nurses and inform nurses to improve their skills.
\end{abstract}

\section{Key words: Staff Nurses \&Productivity.}

\section{Introduction}

Productivity is a critical determinant of health care system performance; it contributes to our overall quality of life and standard of living. Thus, the citizens of a highly productive country will have a better standard of living than people in a less productivity country. Managers and workers would be satisfied if increased productivity resulted in adequate financial rewards. Productivity is influenced by work group dynamics, especially with collaboration.

Nursing as service field, is highly labor-intensive, making nursing management particularly challenging because of the wide variety of experience and educational backgrounds of the employees in the health care setting. The types of work, as well as the workers, challenge the nurse manager to create the kind of environment that facilitates quality nursing practice. The nurse has specific responsibilities to the organization. The beginning nurse will contribute to the success of the unit's efficiency by being aware of the manager's role

\section{(Grohar \& Droce,2005).}

Productivity has become a day-to-day concern for managers. Also, it is the key that opens the door to management action and reward programs. Productivity gains mean a higher standard of living, shorter working hours, longer vacations, bigger paychecks and more fringe benefits (Dunham-Taylor \& Pinczuk, 2006).
The nurse is accountable for excellence in the clinical practice of nursing and the delivery of patient' care on a selected unit within a health institution. This function (clinical practice) is the primary focus of the nurse to meet this responsibility. The nurse has the authority to plan and implement strategies and programs consistent with the organizational policies, goals and objectives, as well as with professional standards. She is responsible for maintaining a safe and caring environment that promotes health teaching, assessing patients and families, response to nursing care as well as evaluating the effectiveness and quality of care and services (Sullivan, 2009). Productivity is the organization's output of products and services divided by its input (Daft, 2000). Productivity is defined as the contribution made towards an organizational end results in relation to the amount of resources consumed (Mc Yu, 2007). Productivity of nurses is an important issue. Hospitals do not report Nurses' productivity data (O' BrienPallas et al., 2004). Productivity measures both quantitative and qualitative factors such as goal attainment and work accomplished ( $\mathbf{O}^{\prime}$ Brien-Pallas et al., 2008).

Productivity of individual nurses has been rarely studied; more attention has been given to the relation between organizational performance and work unit effectiveness and patient outcomes (Maniadakis \& Thananssoulis, 2004). Productivity can be calculated 
by dividing the provided staff hours by the required staff hours. Improvement of productivity can be increased by increasing the provided staff hours while holding the required staff hours constant (Xiao, et al., 2010). The easiest method for controlling labor input is to measure the requirement for care then schedule nursing personnel to meet the expected demands (Sullivan \& Decker, 2005).

Nurses are responsible for improving nursing productivity within the hospital environment. Also use every opportunity to build a productive and cohesive team (Schuhmann, 2008).

\section{Aim of the Study}

Measure staff nurses' productivity.

Subject and Methods

The methodology pursued in the conduction of this study is portrayed according to the following designs:

- Technical design.

- Administrative design.

- Operational design.

- IV-Statistical design.

Technical design

This design involves the study design, sample, setting, and tools of data collection.

\section{Study design}

Descriptive, analytical designs were followed in the conduction of the study.

\section{Setting}

The study was carried out at casualty, post operative (ICUs), medical units, and surgical units at main Assiut University Hospital.

\section{Subject}

The study subject consisted of all staff nurses working at general medical units, surgical units, casualty ICU and post operative ICU at main Assiut University Hospital during the period of data collection (6 months). Their total numbers were 95 staff nurses, their qualifications nursing diploma school.

Tools of data collection

Tools consisted of the following parts:

Part I: Socio-demographic data: This part involved socio-demographic data of nurses to collect information about nurses working in the designated units: unit, sex, age, years of experience and education.

Part II: Nursing activity analysis: An observation of the nurses to monitor the actual time of patient care every 15 minutes for 6 days work period during period of data collection.

Calculating productivity of the staff nurses: were done by using the following formula

$$
\text { Productivity }=\frac{\text { Actual hours }}{\text { Target hours }} \mathbf{x} \text { period of time Certain }
$$

(Armstrong, 2001)

Productivity is the percentage of:

- The actual time: Observe nurse and every 15 minutes write what she done briefly. Total the number of times of performed activity. Convert observations to hours by divide them by 4 , the total number of observations entered for each level (the skill required in performing task). Convert hours to percent by dividing the number of hours for each level by the total number of hours for all levels for each category. The actual time spent (as observed) during 6 hours of the period of data collection.

-Target hours: The time that must be spent (as expected).

\section{II - Administrative design}

Official approval to carry out this study obtained from the hospital director, nursing director of Assiut University Hospital, the heads of designated units, and finally from the nurses who participated in the study of the selected units.

\section{Ethical considerations:}

-The study proposal took agreement from the ethical committee in the faculty of nursing -Assiut University.

-Letters of approval to the heads of selected units.

- Approvals of the selected nurses for helping in data collection were secured.

- Nurses have the right to participate or to refuse in the present study, and then oral agreement was obtained from participated nurses.

- Confidentiality of obtained information.

- The nature and purpose of the study explained to all different participants.

III- Operational design

\section{Preparation phase}

This phase included the following:

- Reviewing the available literature concerning the topic of the study.

- Performing needed modification and translation and retranslation of the tools.

\section{Phases of data collection}

The data collection of the present study was carried out within six months period started from May to August 2011. Data collected by the researcher herself and the help of four newly graduated registered nurses to participate in observation after training them before the starting of data collection. The training included: Explaining item included in the study, accompanying the selected nurses while collecting the data in the shift after assuring that they understand the tool correctly, and worked with them to collect the real data. 
Socio-demographic data to collect information about nurses used through personnel interview with each one. The interview took about 10 minutes for each one. Observation of nurses at the morning shift only from 8 am: 2 pm every 15 minutes ( 6 hours per day) for 6 days period by the different activities including areas and skill levels of such activity. The areas of activities were patient, staff and unit centered activities. Skill levels of activities were administration, nursing, clerical, dietary, housekeeping, messengers and unclassified.

\section{Statistical design}

Statistical analysis

Data entry and statistical analysis were done using SPSS 16.0 statistical software package. Data management was done according to the guidelines of US Department of Health, Education, and Welfare (USDHEW, 1964). Data were presented using descriptive statistics in the form of frequencies and percentages for qualitative variables, and means and standard deviations for quantitative variables. Qualitative categorical variables were compared using chi-square test. Whenever the expected values in one or more of the cells in a $2 \times 2$ tables was less than 5, Fisher exact test was used instead. In larger than $2 \times 2$ cross-tables, no test could be applied whenever the expected value in $10 \%$ or more of the cells was less than 5. Spearman rank correlation was used for assessment of the inter-relationships among ranked variables. Statistical significance was considered at $\mathrm{p}$-value $<0.05$. 


\section{Results}

Table (1): Socio demographic characteristics of the staff nurses.

\begin{tabular}{|c|c|c|}
\hline & \multicolumn{2}{|c|}{ Staff nurse $(n=95)$} \\
\hline & No. & $\%$ \\
\hline $\begin{array}{l}\text { Age(years) } \\
<30 \\
30+\end{array}$ & $\begin{array}{l}44 \\
51\end{array}$ & $\begin{array}{r}46.33 \\
53.7\end{array}$ \\
\hline Mean \pm SD & \multicolumn{2}{|c|}{$31.3 \pm 8.0$} \\
\hline $\begin{array}{l}\text { Sex } \\
\text { Male } \\
\text { Female }\end{array}$ & $\begin{array}{l}19 \\
76\end{array}$ & $\begin{array}{l}20.0 \\
80.0\end{array}$ \\
\hline $\begin{array}{l}\text { Marital status } \\
\text { Single } \\
\text { married }\end{array}$ & $\begin{array}{l}17 \\
78\end{array}$ & $\begin{array}{l}17.8 \\
82.2\end{array}$ \\
\hline $\begin{array}{l}\text { Educational level } \\
\text { Bachelor degree } \\
\text { Diploma in nursing }\end{array}$ & $\begin{array}{l}0.0 \\
95\end{array}$ & $\begin{array}{c}0.0 \\
100\end{array}$ \\
\hline $\begin{array}{l}\text { Years of experience } \\
10+ \\
<10\end{array}$ & $\begin{array}{l}38 \\
57\end{array}$ & $\begin{array}{l}40.0 \\
60.0\end{array}$ \\
\hline Mean \pm SD & & \\
\hline
\end{tabular}

Table (2): Activities observed among staff nurses during six days by areas and levels .

\begin{tabular}{|c|c|c|c|c|c|c|c|c|}
\hline \multirow{2}{*}{ levels } & \multicolumn{7}{|c|}{ Areas } & \multirow[b]{2}{*}{ Total } \\
\hline & $\mathbf{N}$ & $\overline{\mathbf{A}}$ & $\mathbf{C}$ & $\mathbf{D}$ & $\mathbf{H}$ & $\mathbf{M}$ & $\overline{\mathbf{U}}$ & \\
\hline \multicolumn{9}{|l|}{ Patient centered } \\
\hline Giving care & 4292 & 0 & -- & -- & $\begin{array}{ll}-- & \\
\end{array}$ & -- & -- & 4292 \\
\hline Other direct activities & 465 & 1 & -- & $\overline{--}$ & $\overline{--}$ & -- & 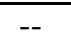 & 466 \\
\hline Exchange of information & $\mathbf{0}$ & 275 & -- & -- & -- & -- & -- & 275 \\
\hline Indirect care & 628 & 19 & 815 & -- & -- & 76 & -- & 1538 \\
\hline Personnel centered & -- & -- & -- & -- & -- & -- & -- & 0 \\
\hline personnel: other & -- & 0 & 4 & -- & -- & -- & -- & 4 \\
\hline \multicolumn{9}{|l|}{ Unit centered } \\
\hline Environment & -- & 0 & -- & -- & 2 & -- & -- & 2 \\
\hline supplies and equipment & 2 & 0 & 77 & 9 & 4 & 113 & -- & 941 \\
\hline other unit activities & -- & 395 & 28 & -- & -- & -- & -- & 423 \\
\hline \multicolumn{9}{|l|}{ Other centered } \\
\hline personnel & -- & -- & -- & -- & -- & -- & 511 & 511 \\
\hline Total & 5387 & 690 & 1624 & 9 & 42 & 189 & 511 & 8452 \\
\hline
\end{tabular}


Table (3): Duration of activities observed among staff nurses during six days by areas and levels (minutes).

\begin{tabular}{|c|c|c|c|c|c|c|c|c|}
\hline \multirow{2}{*}{ levels } & \multicolumn{7}{|c|}{ Areas } & \multirow[b]{2}{*}{ Total } \\
\hline & $\mathbf{N}$ & $\mathbf{A}$ & $\mathbf{C}$ & $\mathbf{D}$ & $\mathbf{H}$ & $\mathbf{M}$ & $\mathbf{U}$ & \\
\hline \multicolumn{9}{|l|}{ Patient centered } \\
\hline Giving care & 64380 & 0 & -- & -- & -- & -- & -- & 64380 \\
\hline Other direct activities & 6975 & 15 & -- & -- & -- & -- & -- & 6990 \\
\hline Exchange of information & 0 & 4125 & -- & -- & -- & -- & -- & 4125 \\
\hline indirect & 9420 & 285 & 12225 & -- & -- & 1140 & -- & 23070 \\
\hline \multicolumn{8}{|l|}{ Personnel centered } & 0 \\
\hline personnel: other & -- & 0 & 60 & -- & -- & -- & -- & 60 \\
\hline Unit centered & -- & -- & -- & -- & -- & -- & -- & \\
\hline Environment & -- & 0 & -- & -- & 30 & -- & -- & 30 \\
\hline supplies and equipment & 30 & 0 & 11655 & 135 & 600 & 1695 & -- & 14115 \\
\hline other unit activities & -- & 5925 & 420 & -- & -- & -- & -- & 6345 \\
\hline \multicolumn{9}{|l|}{ Other centered } \\
\hline personal & -- & -- & -- & -- & -- & -- & 7665 & 7665 \\
\hline Total & 80809 & 10350 & 24360 & 135 & 630 & 2835 & 7665 & 126780 \\
\hline
\end{tabular}

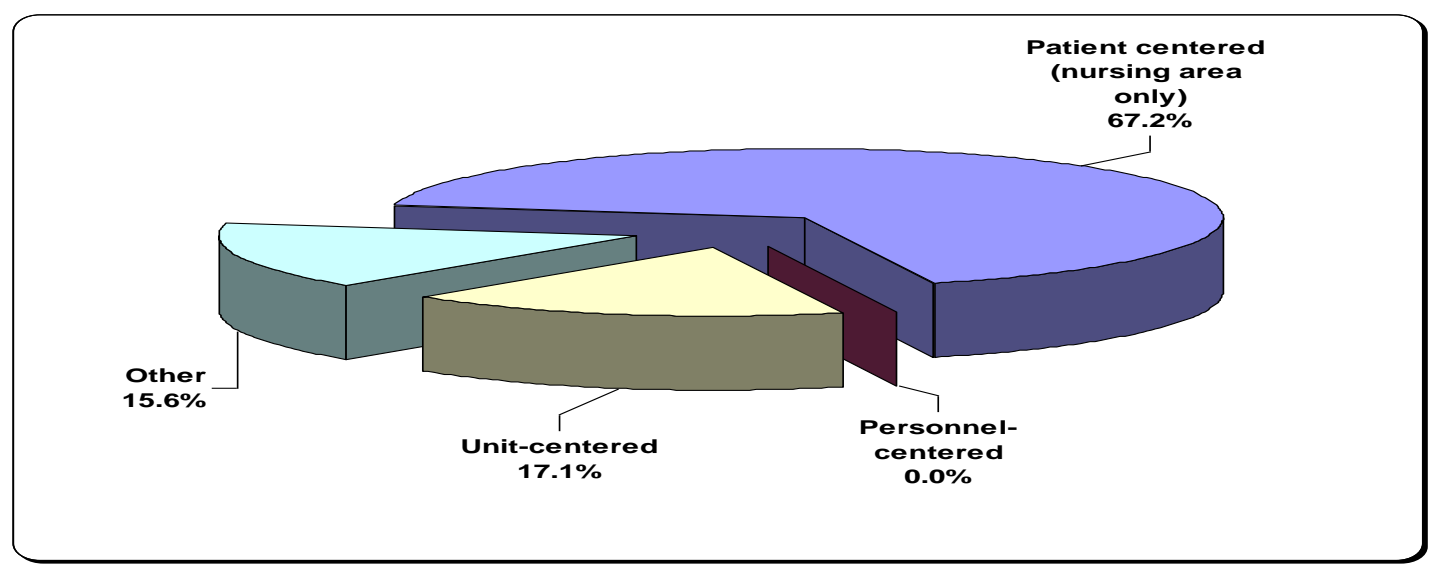

Figure (1): Observed activities performed by nurses during six days by areas .

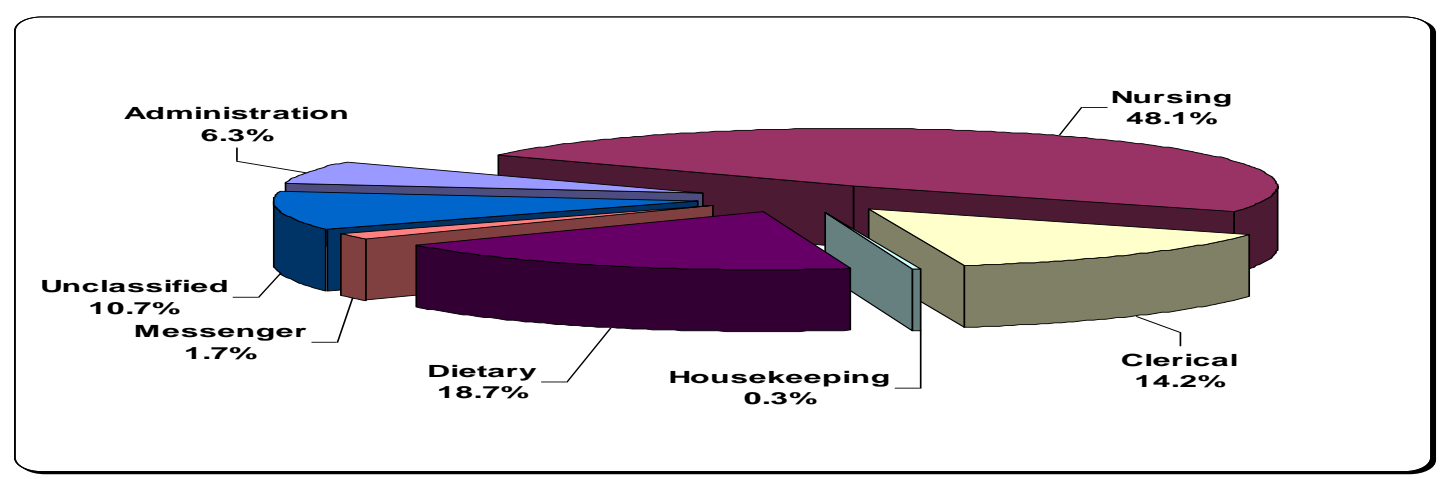

Figure (2): Percentage of time spent in observed activities performed by nurses by levels. 


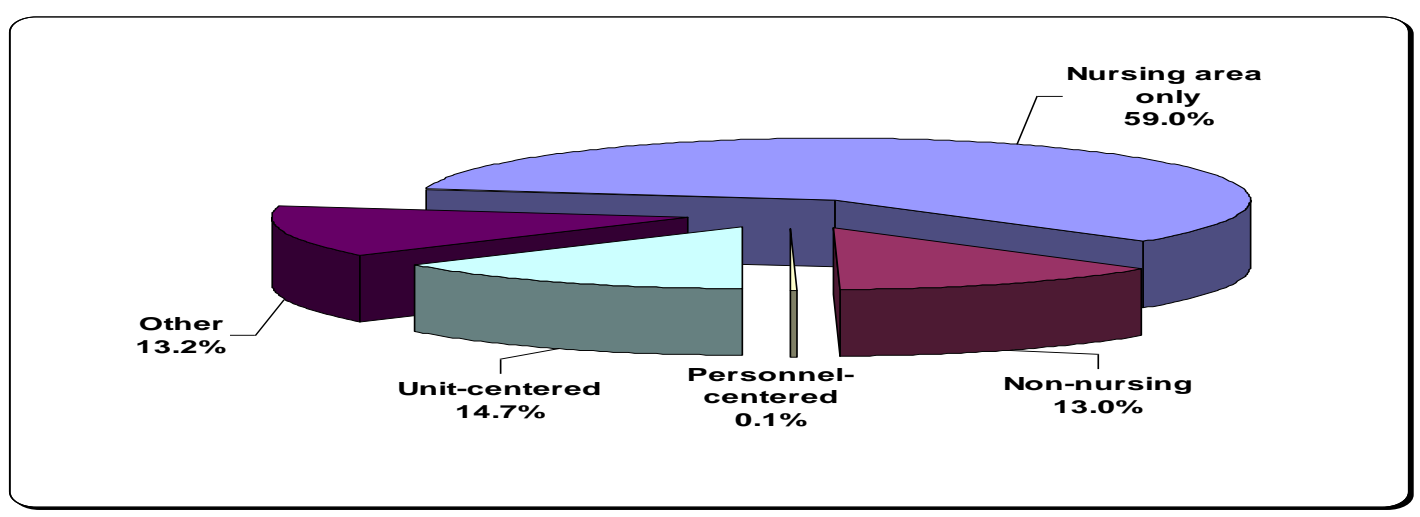

Figure (3): Percentage of time spent in observed activities performed by nurses by areas.

Table (4): Productivity of staff nurses in the selected units.

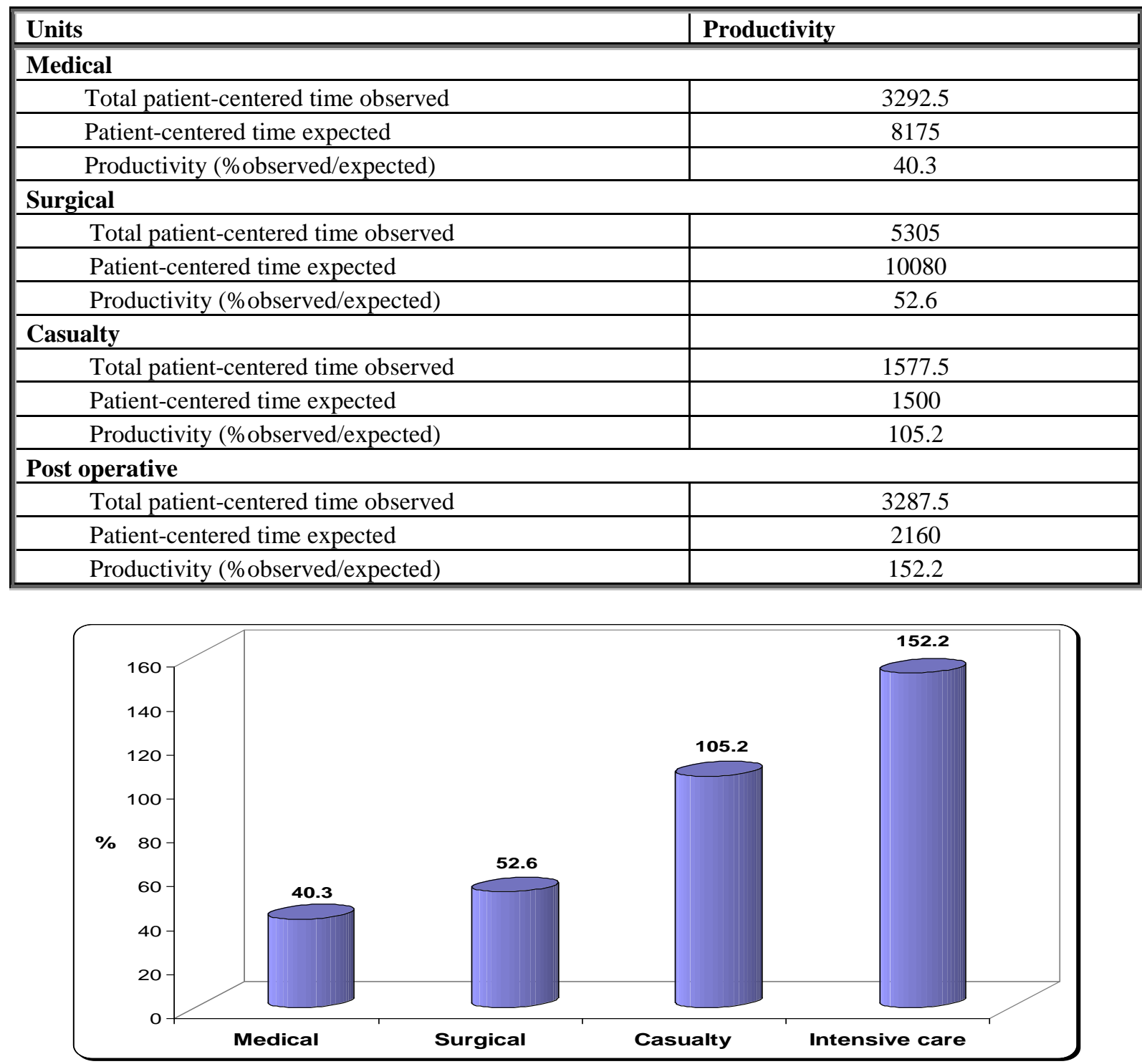

Figure (4): Productivity of nurses in the selected units. 
Table(1):Describes socio demographic characteristics of staff nurses. The table shows that the mean age of nurses was $(31.3 \pm 8.0)$ for staff nurses. Most $(80 \%)$ of the sample were females. Regarding to marital status $(82.2 \%)$ was married. All $(100 \%)$ of staff nurses having nursing diploma school. The mean years of experience was (13.1 \pm 7.4$)$ for

nurses.

Table(2): Shows the total number of activities observed among staff nurses during six days by areas and levels. Table demonstrates that the highest number of activities observed was (4292) times in area of giving care for patient centered activity level, followed by (1538) times observed in area of indirect care for patient centered activity level, regarding to personnel centered activity level it was (4) for clerical skill level, as regards unit centered activity level (941) for supplies and equipment, regarding to other centered activity level (511) for unclassified skill level such as resting, eating.

Table (3): Shows the duration of activities (minutes) observed among staff nurses. Table indicate that (64380) minutes observed among staff nurses for giving care at patient centered activities, regarding to personnel centered activity level it was (60) minutes for clerical skill level, as regards unit centered activity level (14115) for supplies and equipment, while other centered activity level (7665) minutes for unclassified skill level

Figure (1): Shows observed activities performed by nurses during six days by areas. The figure shows that the highest percentage of them (67.2\%) performed at patient centered (nursing area only) activity area followed by $(17.1 \%)$ for unit centered area activity, while $(0.0 \%)$ for personal centered activity area.

Figure (2): Shows percentage of time spent in activities observed performed by nurses by levels. The figure illustrates that less than half (48.1\%) of nurses time spent in nursing activity level, followed by $(18.7 \%)$ in dietary activity level, while $(0.4 \%)$ of nurses time spent in housekeeping activity level.

Figure (3): Shows percentage of time spent in observed activities performed by nurses by areas. The figure demonstrate that more than half $(59 \%)$ of nurses time spent in nursing area only, while $(0.1 \%)$ of nurses time spent in personnel-centered activities. This means that the highest percentage of nurses' time spent at nursing area only.

Table (4): Illustrates productivity of staff nurses. The table shows that productivity was $152.2 \%$ at post operative intensive care unit, while $40.3 \%$ at medical unit.

Figure (4): Illustrates productivity of staff nurses. The figure shows that productivity was $(152.2 \%)$ at post operative intensive care unit, while (40.3\%) at medical unit.

\section{Discussion}

Productivity is the organization's output of products and services divided by its input (Daft, 2000). Productivity also is defined as the contribution made towards an organizational end results in relation to the amount of resources consumed (Yu, 2007). Productivity measures both quantitative and qualitative factors such as goal attainment and work accomplished (O' Brien-Pallas et al., 2008).

Moreover, the ultimate goal of the manager role is to produce high-quality care to a satisfied patient population at low-cost - not directly, but indirectly through the organized efforts of a large, diverse group of professional and non professional staff members (McConnel, 2005), argues that "Achievement of quantifiable goals is the key output of managers (Linna et al., 2010).

The present study findings reveal that more than half of nurses their ages were more than thirty years. Accordingly they have long years of experience. Also the findings show that the mean years of experience for nurses were thirteen. These years of experience mature them with clinical experience, and ability to lead, integrity to grow and foster advancement and adjustment with others.

The current study findings are inconsistent with results reported by the (AANC), (2007) which illustrated that about half of nurses had ten or more years of experience as ICU, about two quarters of them having a Bachelors degree. In addition, the current study findings are inconsistent with Bhagwanjee et al., (2008) study of the audit of critical care resources which reported that more than one quarter of nurses have less than one year to five years of experience.

These study findings showed that the majority of the sample was female nurses, and male nurses constitute small portion of nursing manpower force. Nursing was perceived as a female profession, which reflects the fact that female nurses in Egypt are predominant and male nurses are new comers to the nursing profession. However the situation is now changing because of limited job opportunities in the market, shortage of nurses, and motivated male to enroll in the bachelor program, adding to the factors of public view to nurses started to be positive.

This study results indicated that the majority of staff nurses are having diploma in nursing, Table(1). This finding reflects the fact that large numbers of diploma school nurses are graduated yearly compared to associate degree and other nursing degrees. Bachelor degree and associate degree were compulsory 
assigned to the hospital for two years by the Ministry of Health; however few are directly to the hospital. In relation to observation time spent for each area and level of activities of the nurses units, Tables (3) indicate that (64380) minutes observed among staff nurses at patient centered activities, regarding personnel centered activity level it was (60) minutes for clerical skill level. This means that nurses spent most of their time on patient centered activities.

Figure (2): shows that the highest percentage of activities $(48.1 \%)$ observed among staff nurses at nursing level activity, while $(0.3 \%)$ for housekeeping activity level. The highest percentage of activities (67.2\%) observed among staff nurses at patient centered (nursing area only) activity area, while (0.0 $\%)$ for personal centered activity area. From researcher point of view, the main role of nurse concentrated on patient centered activities, direct patient care (nursing area only).

The current study findings are consistent with results reported by Gabber, (1998) measuring the actual performance of nursing care and patient satisfaction as means of monitoring quality, that indicated higher proportion of time spent by personnel on miscellaneous activity was utilized on standby duties mainly waiting doctors and initiation of medical round. The findings revealed wide variation between time utilized on nursing activities by all categories of nursing personnel and the time devoted by them to non nursing activities. It was evident that, time spent on patient centered was limited compared to time wasted on resting, eating and taking.

In contrast, Lewis, (2009) reported that ten percent of nursing personnel time was spent in reading, drinking tea, or not visibly engaging in an apparent task. Furthermore, Gabber, (1998) results contradict with the current study results. Gabber results showed that nurses spent $27.88 \%$ of their time regarding to other direct activities on medical unit, surgical unit. This means that nurses spent most of their time on areas not related to other direct activities such as clerical and messenger activities.

The current study results in accordance with a study done by Williams et al., (2009) about quantitative analysis of nursing activity, which revealed that a total of 8883 nursing activities were observed and recorded as follows: (46\%) direct patient care, $(25 \%)$ indirect patient care, (10\%) unit related and (19\%) personal time.

This was in consistent with another study done by Harrison \& Nixon, (2006): Nursing activity in general intensive care, the study revealed that $(85 \%)$ direct patient care and up to $6 \%$ of time was spent undertaking non-nursing activities, $(21 \%)$ managerial and administrative activities, this reduce the amount of time spent in direct care.
This is consistent with a study done by Norrie (2009): nurses' time management in intensive care, which reported that nurses spent $(85 \%)$ of their time in four categories of activities (direct patient care $24 \%$, clerical $17 \%$, patient assessment $38 \%$ and time out, patient focused activity 6\%). Linden \& English, (2000) found that nurses spent $27.5 \%$ of their time in direct care, $41.8 \%$ in indirect care, $15 \%$ in unit related activities and $15.7 \%$ in personal time. Abbey, (2012) used work sampling technique to assess time allocation to various activity of the staff nurse. Results indicated that $31 \%$ of nursing time was spent in direct care, $45 \%$ in indirect care and $10 \%$ in unit related activities, $13 \%$ in personal time, $1 \%$ in unknown.

Regarding nursing productivity Figure (4), the present study revealed that the highest percentage of productivity $(152.2 \%)$ was observed at post operative intensive care unit, while the lowest percentage at medical department. The current study results are consistent with O'Brien-Palls, et al., (2004) study of evidence- based standards for measuring nurse staffing and performance at hospital which reported a target of eighty five percent unit productivity on a daily basis. Productivity less than that will results poor quality and higher costs. Nationally in Egypt, a study conducted by Aref,

(2000) in El-minya University hospital to measure the level of productivity of staff nurses working in surgical units (general and private) revealed that level of performance in general surgical unit was $55.7 \%$, and in private surgical units was 61.6\%. Finally Aref described the level of performance and productivity of staff nurses as low.

In the same line, a study conducted by Rajab (2013) study about nurses' workload and its impact on nurses' productivity. The study revealed that performance ratio was (51\% and $75 \%)$ for trauma and post operative ICUs respectively. The results showed that, nurses' performance at trauma was low, while it was high at post operative ICU.

\section{Conclusions}

Regarding duration of activities (minutes) observed among staff nurses, (64380) minutes observed among staff nurses for giving care at patient centered activities, while other centered activity level (7665) minutes for unclassified skill level. Regarding time spent by the nurse in the area and level less than half $(48.1 \%)$ of nurses time spent in nursing activity level, followed by $(18.7 \%)$ in dietary activity level, while $(0.4 \%)$ of nurses time spent in housekeeping activity level. Regarding nursing productivity were $(40.3 \%$, $52.6 \%, 105.2 \%, 152.2 \%$ ) at medical units, surgical unit, casualty intensive care unit, post operative ICU 
respectively. The lowest percent of productivity at medical unit, surgical unit, post operative intensive care unit, while the highest percent at casualty ICU (Acceptable range of productivity $85 \%: 115 \%$ less or more range consider unproductive and patient not receiving required hours of care).

\section{Recommendations}

- Providing training program for nurses to improve performance, decrease waste time, and increase patient care time.

- Productivity should be periodically measured to monitor the performance of nurses and head nurses should train nurses to improve their skills.

\section{References}

1. Abbey, M., Chaboyer, W., Mitchchell, M., \& Ed, G., (2012): Understanding the work of intensive cares nurses: time and motion study. Australian critical care; 25(1):13-22.

2. American Association of critical care nurses (2007): Membership demographic. Retrieved January 2011: http: / / www.aacn.org/aacn/ Membership.nsf Files/ Membdemographic/ file/ Membdemographicpdf

3. Aref, S., (2000): Measuring the level of nurse productivity of staff nurses in general surgical unit in Elminya University Hospital, Doctorate thesis, faculty of nursing, Assiut University. Egypt.

4. Armstrong, M., (2001): A hand book of management techniques. $3^{\text {rd }}$ ed, kogan page limited, London. P. 142-727.

5. Bhagwanjee, S., Scribante, J., (2008): National audit of critical care resoures: How long before we act? Southern African journal of critical care: $24(1): 4-6$.

6. Daft, R., (2000): Management ${ }^{5 \text { th }}$ ed. 503:530.

7. Dunham-Taylor, J., \& Pinczuk, J., (2006): Health care financial management for nurse manager : merging the heart with the dollar. Patient classification system, chapter 19, Pp. 713760: productivity, chapter $21, \mathrm{Pp} .827-857$ by jones and Bartlett. USA.

8. Gabber, E., (1998): Relation between adequacy of nursing care and patient satisfaction at Assiut University Hospital, Doctorate thesis, faculty of nursing, Assiut University. Egypt.

9. Grohar, M., \& Droce, H., (2005): Leadership and management in nursing. $4^{\text {th }}$ ed. Prentice Hall-upper saddle rivers, New Jersey, chapter (7): 151-156.

10. Harrison, S., Nixon, M., (2006): Dependency of elderly people and staffing ratio, Health and
Social services Journal, 88, 4653, supplement pages 15-20.

11. Lewis, S., (2008): They still make house calls. Nursing Outlook,; 23(6): 357-400.

12. Linden, L., English, K., (2000): Adjusting the cost-quality equation: Utilization work sampling and time study data to redesign clinical practice J. Nurs care Qual. 8(3):34-42.

13. Linna, P., Vietnam, H., Pekkola, S,. Ukko J., \& Melkkas, H., (2010): Defining and measuring productivity in the public sector: managerial perceptions. International journal of public sector management: 23(5):479-499.

14. Maniadakis, N., \& Thananssoulis, E., (2004):Acost malmquist productivity index. Eurpean journal of operational research :( 154):396-409.

15. McConnel, C., (2005): Motivating your employees and yourself. Health care manager: 24(3)284-292.

16. Norrie (2009): Nurses' time management in intensive care.Nurs Crit Care. 1997 May-Jun; 2(3):121-5.

17. O'Brien-pallas, L., Murphy, G., Shamian, G., (2008): Understanding the cost and outcomes of nurses turn over in Canadian Hospitals, (nursing turn over study). Final report number (66350) by nursing health services research unit. Retrieved December $\quad 22 \quad 2010 \quad$ from :http://www.nhsru.com/wpcontent/uploads/Canadian-nursing-turnoverstudy-final-reportpdf

18. O'Brien-pallas, L., Thomson, D., McGillis Hall, Pink, G., (2004): Evidence-based standard for measuring nurse staffing and performance Pp. 1-22 by Canadian health services research foundation. Ottawa. Retrieved December 22 2010 from: http: / / www.chsrf.ca/final_research/ogc/pdf/obrien_fina l.pdf

19. Ragab, O., (2013): Nurses work load and its impact on productivity in trauma and post operative intensive units at Assiut University Hospital, Doctorate thesis, faculty of nursing, Assiut University. Egypt.

20. Schuhmann, T., (2008): Hospitals financial Performance: Trends to Watch: financial indicators derived from Medicare cost report data are tools for assessing the effectiveness of a hospitals operation. health financial management . CBS Interactive Businness net work.december 25

from:http://findartcles.com/p/articles/mi-

(2010) m3257/is-7-62/ai-n28072663/?tag=content:coll 
21. Sullivan, E., (2009): Leadership and management. $3^{\text {rd }}$ ed. Spring House Corporation, chapter (1).

22. Sullivan, E., Decker, P., (2005): Effective leadership management in nursing.6 th ed. Handling staffing and scheduling, chapter 17 by upper caddle River, Prentice Hall.USA.

23. Williams, T., (2009): work based learning: A leadership development example from an action research study of shared governance implementation. J Nurs Manag; 13(6): 90-9.

24. Xiao, T., Sanderson, P., Clayton, S., \& Venkatesh, B., (2010): The ETTO Principle and organizational Strategies: a field study of ICU bed and staff management. Journal of cognition, technology and work: 12(2):143-152.

25. Yu, M., (2007): The capacity productivity change and the variable input productivity change: A new decomposition of the Malmquist productivity index. Applied mathematics and computation ;( 185):375-381. 